SCADidoc

\section{Oral Hygiene Practices, Prosthetic Status And Treatment Need Of The General Population Of Arcot (Vellore, Tamil Nadu)}

Syed Ali Peeran1*, Sunil Kumar²

Doctorate Student, Department of Prosthodontics, Maharaj Vinayak Global University, Jaipur, Rajasthan, India.

${ }^{2}$ Professor \& Head, Department of Prosthodontics, Maharaj Vinayak Global University, Jaipur, Rajasthan, India.
Research Article

\title{
Abstract
}

Introduction: Oral health is always an inseparable part of general health and awareness plays a vital role in determining the oral health of an individuals. This study was conducted to determine the oral hygiene practices, prosthetic status and prosthetic needs of general population of Arcot.

Materials and Methods: This population based cross-sectional survey was conducted among adults of Arcot. 4 urban and 4 rural areas were randomly selected. The data was collected from various public places such as schools, households, hospitals, hostels, colleges and various other places of work. Only adults were included in the study so that the results represent the status of the whole sample rather than particular age groups. The questionnaire was prepared which enquired about the age, gender, oral hygiene practices, deleterious habits, prosthetic status and needs. A single calibrated examiner with the help of an assistant examined the samples.

Results: A total of 6982 subjects were examined, where the mean age of the participants was $39.70 \pm 17.5$ years (Range: 18-99) and 4688(67.1) were males and 2294 (32.9) were females. Whereas majority of the patients brushed their teeth $(68.6 \%), 21.5 \%$ had no brushing habits. Out of those who brushed, $68.7 \%$ brushed only once daily. $12.9 \%$ used interdental aid and only $0.3 \%$ used oral rinses. About 51.1\% used chewing stick- either neem twig or miswak. In the present study, only 13.8 percent were smokers, $13.1 \%$ used smokeless tobacco and only $8.1 \%$ percent of the samples consumed alcohol regularly. Majority of the participants had no prosthesis, for both the maxillary 83.7\%and mandibular arch $85.9 \%$. About $58.2 \%$ needed prosthesis with rest to upper jaw and $58.3 \%$ with respect to the lower jaw.

Conclusion: The oral hygiene status of the population was poor.Most of the prosthetic needs of the studied population were unmet, with prosthetic needs being approximately two-fold greater than the prosthetic status.

Keywords: Prosthetic Status; Prosthetic Needs; Oral Hygiene; Oral Disease.

\section{Introduction}

Improving oral health and reducing the negative effect of oral disease on overall health and well-being are major health priorities for medical and dental care providers.[1] Oral diseases such as dental caries, gingivitis and periodontal infection are prevalent conditions that affect a person's oral health and can lead to tooth loss.1 Regular oral hygiene practices are important components of oral health care.1Brushing and flossing are practices to maintain good dental health, along with regular dental visits.[2] Good oral hygiene practices take only minutes a day and save more than $\$ 4$ billion per year in treatment costs. [3]
Loss of teeth adversely affects dietary intake and nutritional status of individuals and could be a distressing experience for many. [4, 5] Tooth loss constitutes a final common pathway for most dental diseases and effects chewing ability, digestion, aesthetics, and as a result, their quality of life.[6] In order to prevent or improve the oral health-related quality of life, it is recommend to replace the teeth with either a fixed or removable prosthesis. [7] The estimation of treatment need is an important requirement in oral health care planning.

People living in developing countries, and concomitantly, of lower socio-economic status have a lacuna in oral health awareness

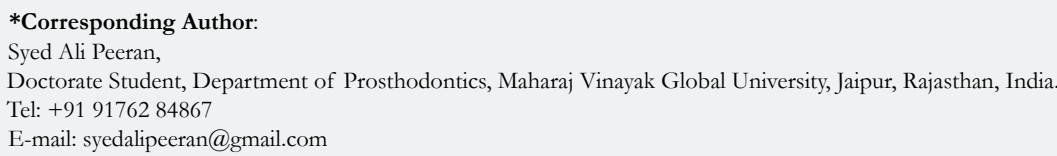

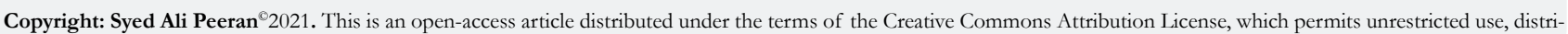
bution and reproduction in any medium, provided the original author and source are credited. 
mirrored in their practice of oral hygiene habits. Very few studies have been conducted in the Arcot (Vellore city Tamil Nadu) about the oral hygiene practices, prosthetic status and prosthetic needs of the population. The available data is scanty. We conducted a study to examine oral hygiene practices of the general population of Arcot. We also aimed to determine the prosthetic status and needs of the general population.

\section{Materials And Methods}

Basic profile of Study area: Arcot is located at $12.9^{\circ} \mathrm{N} 79.33^{\circ} \mathrm{E}$. It has an average elevation of 164 meters (538 ft). Arcot Town has a $7.49 \mathrm{~km}^{2}$ area with a population of 70000 as per the 2011 census. The Municipal office is situated nearly $1 / 4 \mathrm{~km}$ east from the bus stand. The town is located on the southern bank of Palar River, easily accessible from the capital of Tamil Nadu. Chennai is within $120 \mathrm{~km}$ and the district headquarters are within $25 \mathrm{~km}$. Arcot has been developing as a commercial center for long time as it is connected to Chennai and Vellore by the National Highways-46 Ranipet to Krishnagiri Road (Arani to Chennai) passing through this town. Besides this, tourists see nick beauty namely Delhi Gate. This generates floating population to this town.[8]

Sampling Design: The population to be studied was selected from the geographical boundaries of Arcot. A simple random sampling was carried out.

Urban area: The following urban areas i.e., Arcot Municipality, Timiri Town panchayat, Vilapakkam town panchayat, Tajpura Census Town in the Arcot city were selected randomly.

Rural area: The following rural areas i.e., Agaram, Aroor, Durgam, Irungur, around Arcot city were selected randomly.

\section{Obtaining approval from the authorities}

Before the start of the study official permission was obtained from the concerned authorities. Ethical clearance to conduct the study was issued by the ethical clearance board, scientific committee, Faculty of Dentistry, Maharaj Vinayak Global University, Jaipur, Rajasthan.

\section{Study population, sampling and data collection:}

The target population is general population of Arcot (Vellore city Tamil Nadu). Verbal consent to participate in the study will be taken from the participants, being assured that they will remain anonymous concerning their personal data. The data was collected from various public places such as schools, households, hospitals, hostels, colleges and various other places of work. All age groups were included in the study so that the results represent the status of the whole sample rather than particular age groups.

\section{Questionnaire:}

A single page questionnaire was designed to be used to assess the oral hygiene practices habits and systemic diseases. The questionnaire is prepared in English, it was translated into vernacular language and retranslated into English to evade language errors. (Refer to Appendix-1)
The questionnaire enquires about the age, gender, oral hygiene practices, deleterious habits, prosthetic status and needs.

\section{Examiner and examination}

A single calibrated examiner with the help of an assistant examined the sample. W.H.O Type 3 examination was carried out. Examinations were carried out in the nearest public dental center with natural light to reduce diagnostic bias.

\section{Statistical analysis}

The data was presented as number and $\%$ for the categorical variables. SPSS was used for statistical analysis.

\section{Results}

In the present study a total of 6982 subjects were examined, where the mean age of the participants was $39.70 \pm 17.5$ years (Range: 18-99) and 4688(67.1) were males and 2294 (32.9) were females.

Whereas majority of the patients brushed their teeth $(68.6 \%)$, $21.5 \%$ had no brushing habits. Out of those who brushed, $68.7 \%$ brushed only once daily. $12.9 \%$ used interdental aid and only $0.3 \%$ used oral rinses. About $51.1 \%$ used chewing stick- either neem twig or miswak (Table 1). In the present study, only 13.8 percent were smokers, $13.1 \%$ used smokeless tobacco and only $8.1 \%$ percent of the samples consumed alcohol regularly.(Table 2)

Majority of the participants had no prosthesis, for both the maxillary $83.7 \%$ and mandibular arch $85.9 \%$. (Table 3) $58.2 \%$ needed prosthesis with rest to upper jaw and $58.3 \%$ with respect to the lower jaw. (Table 4)

\section{Discussion}

The prosthetic status and need in the general population have not been addressed increasingly in the past years, in many parts of the country. A simple and lucid way of discussing the oral health status of a given population is to describe the percentage of dentate and edentulous subjects. Very few studies have been conducted about the prosthetic status and needs of general population as most of the studies are conducted either on elderly age groups or old age home inmates or special populations, but this study aims at knowing the prosthetic status and needs of the general population as teeth are important in all ages of life. This study was conducted in Arcot region, Vellore district in Tamil Nadu.

In the present study a total of 6982 subjects were examined, where the mean age of the participants was $39.70 \pm 17.5$ years and 4688(67.1\%) were males and $2294(32.9 \%)$ were females. We studied the general population with age ranging from 18-99.

Whereas majority of the patients brushed their teeth $(68.6 \%)$, $215 \%$ had no brushing habits. Out of those who brushed, $68.7 \%$ brushed only once daily. $12.9 \%$ used interdental aid and only $0.3 \%$ used oral rinses. About $51.1 \%$ used chewing stick- either neem twig or miswak. This shows that the oral hygiene practices were poor in our study. Surveys done in many parts of the world have found tooth brushing to be the best way to maintain oral health. [9] A study by Aggnur, M., et al.[10], Valsan, I., et al [11] and 
Table 1. Distribution of respondents according to oral hygiene practices.

\begin{tabular}{|c|c|c|}
\hline Oral hygiene practices & Number & Percentage \\
\hline Only tooth brush & 688 & 9.9 \\
\hline Brush with tooth paste & 4791 & 68.6 \\
\hline No brushing & 1503 & 21.5 \\
\hline \multicolumn{3}{|c|}{ Frequency of brushing per day } \\
\hline Not brushing & 1503 & 21.5 \\
\hline Once a day & 4797 & 68.7 \\
\hline Twice a day & 574 & 8.2 \\
\hline Multiple times per day & 108 & 1.6 \\
\hline \multicolumn{3}{|c|}{ Interdental aid } \\
\hline Used & 900 & 12.9 \\
\hline Does not use & 6082 & 87.1 \\
\hline \multicolumn{3}{|c|}{ Chewing stick (neem twig/ miswak etc.) } \\
\hline Not using & 3409 & 48.9 \\
\hline Using & 3571 & 51.1 \\
\hline \multicolumn{3}{|c|}{ Mouth rinses } \\
\hline Not using & 6964 & 99.7 \\
\hline Using & 18 & 0.3 \\
\hline
\end{tabular}

Table 2. Distribution of respondents according to cigarette smoking.

\begin{tabular}{|c|c|c|}
\hline Smoking & Number & Percentage \\
\hline Absent & 6034 & 86.2 \\
\hline Present & 966 & 13.8 \\
\hline \multicolumn{3}{|c|}{ Smokeless tobacco } \\
\hline Absent & 6064 & 86.9 \\
\hline Present & 918 & 13.1 \\
\hline \multicolumn{3}{|c|}{ Alcohol consumption } \\
\hline Absent & 6420 & 91.9 \\
\hline Present & 580 & 8.1 \\
\hline
\end{tabular}

Table 3. Distribution of respondents according to Maxillary Prosthetic status.

\begin{tabular}{|c|c|c|c|c|}
\hline \multirow{2}{*}{ Prosthetic status } & \multicolumn{2}{|c|}{ Maxillary } & \multicolumn{2}{c|}{ Mandibular } \\
\cline { 2 - 5 } & Number & $\mathbf{\%}$ & Number & $\mathbf{\%}$ \\
\hline No prosthesis & 5846 & 83.7 & 6000 & 85.9 \\
\hline Bridge & 606 & 8.7 & 482 & 6.9 \\
\hline More than one bridge & 230 & 3.3 & 222 & 3.2 \\
\hline Partial denture & 120 & 1.7 & 126 & 1.8 \\
\hline Both bridge and partial denture & 58 & 0.8 & 44 & 0.6 \\
\hline Full removable denture & 120 & 1.7 & 104 & 1.5 \\
\hline Not recorded & 2 & 0 & 4 & 0.1 \\
\hline
\end{tabular}

Bhardwaj, V. K., et al.[12] also showed similar findings with poor oral hygiene practices were being followed by the participants from different parts of India. About half the population used chewing stick in our study. Chewing stick has revealed parallel mechanical and chemical cleansing of oral tissues as compared to a toothbrush. Hence, the influence of chewing stick on the population can be further explored [13].

In the present study, only $13.8 \%$ percent were smokers, $13.1 \%$ used smokeless tobacco and only $8.1 \%$ percent of the samples consumed alcohol regularly. Smoking and tobacco use has a detrimental effect on periodontal health, and several studies have reported a strong dose-dependent association between tobacco smoking and the risk of tooth loss. $[14,15]$ Our study had quite a few participants who used tobacco and consumed alcohol regularly. However, we did not assess the dose response relationship which remains one of the limitations of the study.

Majority of the participants had no prosthesis, for both the maxillary $83.7 \%$ and mandibular arch $85.9 \%$. The most common prosthesis was bridge followed by partial denture. The low proportion of prosthesis was also found in studies by Shenoy RP et al.[16] and Soh et al.[17] The low proportion of prosthesis may be due to the lack of awareness, financial concerns and misconceptions regarding adjustment to prosthesis. 
Table 4. Distribution of respondents according to maxillary and mandibular prosthetic needs.

\begin{tabular}{|c|c|c|c|c|}
\hline \multirow{2}{*}{ Prosthetic status } & \multicolumn{2}{|c|}{ Maxillary } & \multicolumn{2}{c|}{ Mandibular } \\
\cline { 2 - 5 } & Number & $\mathbf{0}$ & Number & $\mathbf{\%}$ \\
\hline No prosthesis & 5846 & 83.7 & 6000 & 85.9 \\
\hline Bridge & 606 & 8.7 & 482 & 6.9 \\
\hline More than one bridge & 230 & 3.3 & 222 & 3.2 \\
\hline Partial denture & 120 & 1.7 & 126 & 1.8 \\
\hline Both bridge and partial denture & 58 & 0.8 & 44 & 0.6 \\
\hline Full removable denture & 120 & 1.7 & 104 & 1.5 \\
\hline Not recorded & 2 & 0 & 4 & 0.1 \\
\hline
\end{tabular}

In the present study only $58.2 \%$ needed no prosthesis with rest to upper jaw and $58.3 \%$ with respect to the lower jaw. Remaining participants needed single unit prosthesis followed by multiunit prosthesis and full mouth prosthesis. Prosthetic need in the present study was $41.7 \%$. Das, D., et al. [18], Patil et al [19] and Aggnur, M., et al.10 had similar study findings, where the prosthetic need was high. Here the prosthetic need was slightly more because the age of the sample contained up to 99 years. Thus, it is concluded that there is lack of dental facilities and lack of dental hygiene in the present study.

To know the prevalence of a disease and the treatment needs are the first step in the right direction to deal with the dental disease. However, our study had certain limitations. Firstly, the study population was conveniently selected hence reducing the external validity of the study. Nevertheless, the study area was selected by random selection and may accurately represent the population of Arcot. A nationwide evaluation of health services should carry out further epidemiological surveys on a larger scale with door-to-door data acquisition related to wealth, religion and caste on individual basis. This helps us to estimate the prosthetic status and need and associated factors. The findings of this study clearly demonstrate a high unmet need for prosthetic care among the general population of Arcot. These results may serve as a baseline reference for the future evaluation of prosthetic status and prosthetic need and as an eye-opener for oral health service providers and decision makers, thereby sensitizing them to the lacunae existing in the provision of oral health care in the general population.

\section{Conclusion}

This is the first study done to determine the prosthetic status and treatment needs of the general population of Arcot. The findings in this study revealed that the population of Arcot had poor oral hygiene status. Unmet prosthetic treatment needs existed in Arcot, indicating the existence of barriers to accessible dental care. A sizeable amount of population is also in need of dental prosthesis and the same needs immediate attention. The present results may serve as a baseline for the future evaluation of attitudes towards replacement of teeth.

\section{References}

[1]. Boggess KA, Urlaub DM, Massey KE, Moos MK, Matheson MB, Lorenz C. Oral hygiene practices and dental service utilization among pregnant women. J Am Dent Assoc. 2010 May;141(5):553-61. Pubmed PMID:
20436103.

[2]. Ahad M, Gheena S. Awareness of tooth brushing techniques and proper oral hygiene among school children. Journal of pharmaceutical sciences and research. 2015 Jun 1;7(6):367.

[3]. DeDonno MA. Dental anxiety, dental visits and oral hygiene practices. Oral Health Prev Dent. 2012;10(2):129-33. Pubmed PMID: 22763591

[4]. KATZ S, FORD AB, MOSKOWITZ RW, JACKSON BA, JAFFE MW. STUDIES OF ILLNESS IN THE AGED. THE INDEX OF ADL: A STANDARDIZED MEASURE OF BIOLOGICAL AND PSYCHOSOCIAL FUNCTION. JAMA. 1963 Sep 21;185:914-9. Pubmed PMID: 14044222.

[5]. Pallegedara C, Ekanayake L. Tooth loss, the wearing of dentures and associated factors in Sri Lankan older individuals. Gerodontology. 2005 Dec;22(4):193-9. Pubmed PMID: 16329226.

[6]. Locker D, Miller Y. Evaluation of subjective oral health status indicators. J Public Health Dent. 1994 Summer;54(3):167-76. Pubmed PMID: 7932353.

[7]. Eachempati P, Shenoy VK, Jain N, Singh S. Prosthodontic status and needs of elderly institutionalized residents in Mangalore: a prospective study. Indian J Dent Res. 2013 May-Jun;24(3):284-8. Pubmed PMID: 24025871.

[8]. Arcot, Tamil Nadu- Wikipedia.

[9]. Pradhan S, Bhat MK. Assessment of periodontal status of rural nepalese population using the community periodontal index. J Nepal Dent Assoc. 2009;10(2):97-104.

[10]. Aggnur M, Garg S, Veeresha K, Gambhir R. Oral Health Status, Treatment Needs and Knowledge, Attitude and Practice of Health Care Workers of Ambala, India - A Cross-sectional Study. Ann Med Health Sci Res. 2014 Sep;4(5):676-81. Pubmed PMID: 25328773.

[11]. Valsan I, Joseph J, Janakiram C, Mohamed S. Oral Health Status and Treatment Needs of Paniya Tribes in Kerala. J Clin Diagn Res. 2016 Oct;10(10):ZC12-ZC15. Pubmed PMID: 27891449.

[12]. Bhardwaj VK, Sharma KR, Jhingta P, Luthra RP, Sharma D. Assessment of oral health status and treatment needs of police personnel in Shimla city, Himachal Pradesh: A cross-sectional study. International Journal of Health \& Allied Sciences. 2012 Jan 1;1(1):20.

[13]. Malik AS, Shaukat MS, Qureshi AA, Abdur R. Comparative effectiveness of chewing stick and toothbrush: a randomized clinical trial. N Am J Med Sci. 2014 Jul;6(7):333-7. Pubmed PMID: 25077082.

[14]. Leite FRM, Nascimento GG, Scheutz F, López R. Effect of Smoking on Periodontitis: A Systematic Review and Meta-regression. Am J Prev Med. 2018 Jun;54(6):831-841. Pubmed PMID: 29656920.

[15]. Carson SJ, Burns J. Impact of smoking on tooth loss in adults. Evid Based Dent. 2016 Sep;17(3):73-74. Pubmed PMID: 27767106.

[16]. Shenoy RP, Hegde V. Dental prosthetic status and prosthetic need of the institutionalized elderly living in geriatric homes in mangalore: a pilot study. ISRN Dent. 2011;2011:987126. Pubmed PMID: 21991492.

[17]. Soh G, Chong YH, Ong G. Dental prosthetic status and needs of an elderly population living in long-term care facilities in Singapore. J Community Health. 1992 Jun;17(3):175-81. Pubmed PMID: 1512308.

[18]. Das D, Suresan V, Jnaneswar A, Khurana C, Bhadauria US, Saha D. Oral health status and treatment needs among the Juang tribe-a particularly vulnerable tribal group residing in Northern Odisha, India: A cross-sectional study. Health Soc Care Community. 2019 Sep;27(5):e752-e759. Pubmed PMID: 31231942.

[19]. Patil VV, Shigli K, Hebbal M, Agrawal N. Tooth loss, prosthetic status and treatment needs among industrial workers in Belgaum, Karnataka, India. J Oral Sci. 2012;54(4):285-92. Pubmed PMID: 23221153. 